\title{
The Role of Self-Awareness and Problem-Solving Orientation for the Instrumentality of Goal-Related Means
}

\author{
Antonia Kreibich ${ }^{1}$, Marie Hennecke ${ }^{2}$, and Veronika Brandstätter ${ }^{1}$ \\ ${ }^{1}$ Department of Psychology, University of Zurich, Switzerland \\ ${ }^{2}$ Department of Psychology, University of Siegen, Germany
}

\begin{abstract}
Successful goal striving hinges on the selection of instrumental means. The current research investigates individual differences in self-awareness as a predictor for means instrumentality. This effect should be mediated by the tendency of self-aware individuals to approach the process of goal pursuit in a way that is problem-solving-oriented. Four studies $\left(N_{1 \mathrm{a}}=123, N_{1 \mathrm{~b}}=169, N_{2}=353, N_{3}=118\right)$ were conducted to explore the positive relation between self-awareness and means instrumentality via heightened levels of problem-solving orientation. Studies $1 \mathrm{a}$ and $1 \mathrm{~b}$ found cross-sectional support for the relation between dispositional self-awareness and problem-solving orientation. Study 2 (preregistered) replicated this finding and provided experimental evidence for the hypothesized mediation model. Finally, Study 3 found longitudinal support that dispositional self-awareness and problem-solving orientation predict self-reported means instrumentality and, beyond this, participants' objective exam grades. This research emphasizes the crucial role of individual differences in self-awareness for an important self-regulatory process, that is, the selection of instrumental means in personal goal pursuit.
\end{abstract}

Keywords: self-awareness, goal, problem-solving, personality, self-regulation

To a large extent, human behavior is driven by goals (Kruglanski et al., 2002). Goals can be defined as desired end-states that individuals strive to attain through action (Carver \& Scheier, 1982). Accordingly, the cognitive representations of goals entail desired outcomes and the means an individual deploys for goal pursuit (e.g., Kruglanski et al., 2002). By definition, means are any activities, behavioral strategies, events, or circumstances that contribute to attaining a goal (Shah \& Kruglanski, 2003). Consequently, goal setting is just the beginning, and goal striving and, most importantly, "choosing the appropriate means is vital for successful goal pursuit” (Bélanger et al., 2016, p. 67).

So far, little research has been done into the role of individual differences in predicting the instrumentality of goalrelated means selected by individuals. In our research, we focus on individual differences in self-awareness, that is, the extent to which individuals turn their attention toward their selves (e.g., Duval \& Wicklund, 1972). Research has so far shown that self-aware individuals adopt a problemsolving orientation when goal pursuit becomes difficult (e.g., Burwell \& Shirk, 2007). Such a problem-solving orientation in goal striving might be especially relevant when no behavioral routines have been established (e.g., during the pursuit of new or vague goals). Successful problem-solving then promotes the selection of instrumental means as they aim at bringing ones' momentary state closer to the desired end-states of ones' goals (e.g., Coats et al., 2014). Hence, we propose that means instrumentality should be promoted to the extent that individuals become self-aware as they then conceive of difficult personal goal pursuit as a problem-solving process and thus are more likely to select instrumental means.

We are presenting the results of four studies investigating the effect of people's self-awareness on their problem-solving orientation (Studies 1a and 1b) and, in turn, on the instrumentality of their goal-directed means (Studies 2 and 3).

\section{The Role of Self-Awareness in Goal Striving}

Self-awareness is defined as a heightened metacognitive focus on the self, namely on one's inner thoughts, feelings, and behaviors. It has been conceptualized and therefore 
differently named both as a trait variable (self-consciousness, Fenigstein et al., 1975; metacognitive self-reflection, Grant et al., 2002; reflection, Trapnell \& Campbell, 1999) and as a state variable (objective self-awareness, Duval \& Wicklund, 1972). Our research uses the broader term selfawareness to include dispositional and situational forms, both of which we investigate. In addition, it is important to note that we investigate the reflective side of self-awareness and not the anxiety-driven side of it, which is rumination (Trapnell \& Campbell, 1999), or forms of non-evaluative awareness and acceptance of the self, which is mindfulness (Evans et al., 2009). The differences between these conceptualizations are mirrored in distinct patterns of relations with personality dimensions: Whereas (reflective) self-awareness is positively associated with openness to experience and conscientiousness (Panah \& Seif, 2014), rumination is positively associated with neuroticism (Costa \& McCrae, 1992), and mindfulness is both negatively associated with neuroticism and positively associated with conscientiousness (Giluk, 2009).

While self-awareness describes an attentional focus toward all kinds of self-related stimuli, several theoretical approaches have especially emphasized the important role of self-awareness for certain stimuli, namely personal goals (e.g., Baumeister et al., 1994; Carver \& Scheier, 1998). Specifically, early work on self-awareness proposed that (chronic or momentary states of) self-awareness also leads people to be more aware of their momentary state in goal pursuit in relation to their ideal state in goal pursuit (i.e., the set goal). This so-called goal monitoring, in turn, is the precondition for detecting discrepancies between the momentary and the ideal goal state (e.g., Baumeister et al., 1994; Carver \& Scheier, 1998; Duval \& Wicklund, 1972). If such a discrepancy is detected, this, in turn, motivates the individual to reduce it. If the discrepancy reduction proceeds automatically or easily (e.g., because instrumental routines have been established), then discrepancy reduction should not constitute a problem to the person. In other cases (e.g., when pursuing new/vague goals or encountering difficulties in goal pursuit), adopting a problem-solving orientation should be beneficial.

So far, however, less is known about the mechanisms underlying goal-related discrepancy reduction if one does not know directly how to do it, for instance, when pursuing new or vague goals. We suggest that bringing a current state in line with the ideal state (i.e., the set goal) requires then a process of goal-related problem-solving. Taking this a step further, we propose individuals who exhibit high levels of self-awareness should be more likely to take on a problem-solving orientation in difficult goal pursuit. This idea that self-awareness promotes a problem-solving orientation is furthermore supported by research demonstrating that introspection, the instruction to verbalize one's thoughts, and individuals' levels of reflective thinking promote problem-solving (Burwell \& Shirk, 2007; Fox et al., 2011; Jäkel \& Schreiber, 2013).

\section{Problem-Solving in Goal Striving}

Historically, the concept of problem-solving is rooted in cognitive psychology, where it is understood as a cognitive skill that enables people to work successfully on well-defined tasks (e.g., Duncker's “candle problem”, Duncker, 1945). Such simple tasks were assumed to represent "real" problems people usually encounter in their everyday life which, actually, is not the case. Thus, in the 1970s, researchers started to investigate more ill-defined problems people encounter in everyday contexts (so-called "everyday problem-solving", Broadbent \& Aston, 1978). Contrary to welldefined problems which have only one correct solution, ill-structured problems have several correct solutions. Ill-defined problems have furthermore three components, whereby one or more are not clearly specified: an initial state, an end state, and the means (e.g., Simon, 1973). Similarly, so-called "complex problem-solving" is defined in cognitive psychology as the process of solving a complex problem with a non-transparent given or goal state and different possible ways of aligning them (Dörner \& Reither, 1978; for an overview, see Frensch \& Funke, 1995). Still, another theoretical conceptualization considers problems as stressors in everyday goal striving, and problem-solving is understood as a (problem-focused vs. emotion-focused) coping strategy to remove or alter the given stressor (Lazarus \& Folkman, 1984). In a nutshell, the main difference between these theoretical approaches are their different disciplinary backgrounds, yet they share certain defining features of a problem, that is, vague elements within the problem and several possible ways to solve it (for an integrative perspective on this literature, see Coats et al., 2014). Thus, we understand problem-solving as a cognitive orientation towards reducing discrepancies between goals and momentary states in goal pursuit necessary when these discrepancies cannot be reduced easily.

Moreover, the different theoretical approaches share assumptions on the features of problem-solving (Coats et al., 2014): First, to find appropriate solutions to solve a problem, all relevant factors that may contribute to coming closer to the goal must first be identified and considered. These factors may lie outside the person (e.g., situational demands) or inside the person (e.g., their cognitive abilities), of which the latter can either be highly domain-specific (e.g., content knowledge) or rather domain-general (e.g., selfregulatory abilities) (Care, 2017; Coats et al., 2014; Frensch \& Funke, 1995). Second, and most importantly to our research, successful problem-solving then occurs by 
selecting instrumental means (e.g., Care, 2017), any activities or strategies that help the solver solve the problem and attain the set goal. Hence, selecting instrumental means is a behavioral consequence of adopting a certain cognitive (problemsolving) orientation in goal pursuit (e.g., Care, 2017). But as one would expect, not all means be equally instrumental.

\section{Means Instrumentality}

Most of the time, people can choose between different means of attaining their goals. For example, a student may prepare for an exam by regularly meeting with likeminded other students to review the material together or by cramming large volumes of material the day before the exam. As illustrated here, not all means may be equally helpful for goal attainment, and selecting instrumental means is crucial for successful goal pursuit.

If multiple, otherwise comparable, means are available for a given goal, a person will probably select the one that is most instrumental according to their subjective belief (Kruglanski et al., 2002). According to goal-systems theory (Kruglanski et al., 2002), the subjective instrumentality of goal-related means depends on the number of additional means that promote the achievement of the focal goal and the number of additional goals that can be attained with a given means. For example, a means that serves non-focal goals in addition to the focal goal is perceived as being less instrumental for that focal goal and is less likely to be selected (Zhang et al., 2007). Furthermore, means are perceived as being particularly instrumental to a focal goal when they fit their goals' motivational orientation toward approach or avoidance (Hennecke, 2019) or detrimental to an alternative goal (Schumpe et al., 2018).

To sum it up, instead of focusing on specific characteristics and constellations of a means or its associated goals, we take a somewhat different perspective in our research and investigate the role of individual differences in means instrumentality. More specifically, we scrutinize the extent to which an individual's self-awareness might foster a problem-solving orientation in difficult goal pursuit - when goals are disturbed by stressors (Study 1a and 1b), vague (Study 2) or new (Study 3) - and, as a consequence, predicts means instrumentality. In doing so, we highlight the importance of considering personality processes to better understand self-regulation (Hoyle, 2010).

\section{The Present Studies}

We hypothesize that self-awareness predicts an orientation toward problem-solving in difficult goal pursuit and, in turn, the selection of instrumental means. First, in order to investigate the correlational relationship between self-awareness and problem-solving orientation, we assessed both variables as part of two larger studies (Studies 1a and 1b) that were originally designed to investigate the role of selfawareness for the identification of goal-related obstacles (for more details, see https://doi.org/10.1002/per.2234). Next, we investigated the hypothesized mediational effect of self-awareness on (subjective) means instrumentality via an increased orientation toward problem-solving in our experimental Study 2. Our last study, a longitudinal study with students, investigated the effect of self-awareness, problem-solving orientation, and (subjective) means instrumentality on an objective indicator of goal performance, namely students' exam grades (Study 3 ).

We computed correlations and hierarchical multiple regressions using the IBM $^{\circledR}$ SPSS ${ }^{\circledR}$ Statistics software (Version 23). Please note that all correlations reported are Pearson's correlations and all $p$-values are two-tailed. Furthermore, we conducted mediation analyses (Studies 2 and 3) with the PROCESS macro for SPSS (Hayes, 2013). Taking into consideration recommendations regarding Open Science (Simmons et al., 2012), we are reporting how we determined our sample sizes, all manipulations, all data exclusions (if any), and all measures in all studies that we conducted. Furthermore, Study 2 was preregistered (our time-stamped preregistration can be found here: https://aspredicted.org/zx5jx.pdf). All supplemental materials, including the study materials, the verbatim wording of all study variables, analyses scripts, results of additional analyses, and datasets, are publicly available on the Open Science Framework (https://osf.io/rngfk/). All supplemental materials, including the study materials, analysis scripts, additional analyses of Studies $1 \mathrm{a}$ and $1 \mathrm{~b}$, and measures and results of two pilot studies are publicly available on the Open Science Framework (https://osf.io/rngfk/). Unfortunately, we could only make the data of Study 2 openly accessible, as the informed consent in the other studies (which we had conducted prior to Study 2) did not inform participants of this possibility. The data of these studies are available on request. All study procedures conformed to the requirements of the local research ethics board.

\section{Studies $1 \mathrm{a}$ and $1 \mathrm{~b}$}

Studies $1 \mathrm{a}$ and $1 \mathrm{~b}$ investigated the first part of our hypothesized causal chain, according to which self-awareness should be associated with a stronger orientation toward problem-solving, which, in turn, should lead to a higher instrumentality of goal-related means. To investigate the association between self-awareness and problem-solving orientation, we assessed these variables as part of two larger studies. Since the two studies differ only with regard to the characteristics of their samples, we will report these 
separately, but the measures and results of the studies together. Furthermore, we will only report the results of the simple correlational analyses here, while all additional analyses considering covariates (e.g., affect, life satisfaction, openness for experiences, conscientiousness, trait self-control, mindfulness, self-efficacy) are reported in the supplemental materials presented on our OSF account. As predicted, the correlation between self-awareness and problem-solving remained significantly positive across all these analyses.

\section{Method}

\section{Study 1a: Participants and Procedure}

Participants for this study were recruited through mailing lists and participated in return for course credit. Based on a $G^{*}$ Power analysis (Faul et al., 1992-2019), a sample size of 123 was required in order to detect the hypothesized effect of the main hypothesis of this study with a statistical power of $80 \%$. We recruited an $N$ of 123 university undergraduates with a mean age of 23.68 years $(S D=7.10,77 \%$ female). In this short online survey, participants were asked to name a personal goal that was important to them and which they had been pursuing for at least 4 weeks. They then answered goal-related questions and completed personality scales. Finally, they provided some sociodemographic information and were debriefed.

\section{Study 1b: Participants and Procedure}

Based on a $\mathrm{G}^{*}$ Power analysis (Faul et al., 2009) regarding the main hypotheses of this study, an $N$ of 105 participants was needed. To increase power, we recruited as many participants as possible within a set period of 5 weeks. In the end, $N=169$ participants (mostly university undergraduates; $M_{\text {age }}=24.09$ years, $S D=7.66,66 \%$ female) took part in this online survey in return for course credit. They were recruited through mailing lists, personal invitations in psychology lectures, and flyers. As in Study 1a, participants named a personal goal and answered goal-related questions and personality scales. At the end of the study, participants provided some sociodemographic background information and were debriefed.

\section{Measures}

\section{Dispositional Self-Awareness}

In both studies, we measured dispositional self-awareness using the 12-item Self-Reflection subscale of the Self-Reflection and Insight Scale (SR-SRIS; Grant et al., 2002). This scale measures different aspects of self-awareness, namely being aware of one's inner feelings (e.g., "I frequently examine my feelings."), one's inner thoughts (e.g., "I frequently take time to reflect on my thoughts."), and one's behavior (e.g., "It is important for me to evaluate the things that I do."). Scales ranged from $1=$ strongly disagree to 6 = strongly agree (Study 1a: $M=4.68, S D=0.78, \alpha=.90$; Study $1 \mathrm{~b}: M=4.61, S D=0.79, \alpha=.91$ ).

\section{Problem-Solving Orientation}

We used the Individual Coping Questionnaire to assess a person's orientation toward problem-solving in personal goal pursuit (INCOPE; Bodenmann, 2000). This questionnaire comprises 21 items measuring both functional (e.g., problem-solving) and dysfunctional (e.g., rumination) forms of coping. Participants were asked how they have dealt with stressful situations to pursue their goals during the last 2 weeks. To assess their problem-solving orientation, we chose to use two items from the original 6-items scale that assess a general orientation to approaching a goal through the process of problem-solving: "I think very carefully about what's going on and what to do" and "I actively influence the situation" (Study 1a: $r=.49, p>.001$; Study 1b: $r=$ $.43, p>.001$ ). (Please note that we repeated all analyses also with the full scale which did not change results.) Scales ranged from $1=$ never to $5=$ often (Study 1a: $M=3.64, S D=$ 0.73; Study $1 \mathrm{~b}: M=3.87, S D=0.66$ ).

\section{Results and Brief Discussion}

As expected, self-awareness and problem-solving orientation were significantly correlated, both in Study 1a, $r=$ $.35, p<.001$, and in Study $1 \mathrm{~b}, r=.32, p<.001$. Linear regression analyses furthermore supported that this association remained positive and significant even when controlling for the influence of potential third variables (results can be found in the supplemental materials on our OSF account). However, given that both Studies 1a and $1 \mathrm{~b}$ were correlational, they only revealed some initial evidence of an association between self-awareness and problem-solving orientation but no evidence for the postulated direction of the association.

\section{Study 2}

Study 2 was conducted to obtain experimental evidence for the full causal chain we predicted. Accordingly, we investigated whether self-awareness predicts means instrumentality through its effect on problem-solving orientation.

\section{Method}

\section{Participants}

Based on Kenny (2017), we expected that a sample of 346 participants would allow us to replicate the small indirect effect of $b=.02$ in the hypothesized mediation model that we found in a pilot study (which is presented in the 
supplemental materials on the OSF account) with $80 \%$ power at a significance level of $5 \%$. Due to the financial possibilities and to retain a large enough sample even after possible data exclusions, we requested 500 participants from MTurk, an Internet-based platform that matches "workers" with "requesters" to participate in online studies in return for compensation. In line with best practice recommendations, the study was only available to US-based workers with an approval rating of over 90\% (e.g., Goodman et al., 2013). Five hundred and four participants took part in this study, but the data of 151 participants were excluded based on exclusion criteria regarding the main study writing task, that is, for not seriously completing the task $(n=46)$, for showing forms of plagiarism (which we checked using PlagScan.com) $(n=56)$, or for writing less than 100 words $(n=49)$. The total number of excluded cases did not differ systematically between the two experimental conditions $(t(502)=-0.544, p=.587)$, with respect to age $(t(149)=-0.059, p=.953)$, gender $(t(149)=0.341$, $p=.733)$, or educational background $(t(149)=0.269, p=$ .788). The final sample included 353 participants with a mean age of 37.73 years $(S D=10.97,49.9 \%$ female) and different educational backgrounds (16\% high school or less; $24 \%$ college; $40 \%$ bachelor's degree; $20 \%$ master's degree or more). Note that the academic background of the participants had no influence on their degree of problem-solving orientation $(t(351)=0.779, p=.436)$, concentration $(t(351)=$ $0.361, p=.718)$, interest $(t(351)=0.655, p=.513)$, and honesty $(t(351)=1.526, p=.128)$, nor on their self-rated instrumentality of their chosen means $(t(351)=-0.683$, $p=.495)$.

\section{Procedure}

This study was designed as an experimental study with one between-subjects factor (experimental condition vs. passive control condition). First, participants received information about the purpose and the content of the study. To prevent drop-outs and improve data quality, we informed participants about the writing task at the beginning of the study (Zhou \& Fishbach, 2016). Afterwards, participants' dispositional self-awareness was assessed. Participants who had been randomly assigned to the experimental condition received a manipulation that has previously been used successfully to enhance situational self-awareness (Kreibich et al., 2020). The instruction was: "While you are writing the text, focus your attention on what you think, feel, and do." In addition, these participants were reminded to stay self-aware while writing the text, using the following instruction: "Please don't forget to observe yourself while writing the text." Participants who had been randomly assigned to the control condition did not receive any instructions at this point. All participants then had to work on a writing task (for more detailed information, see below).
Afterward, they were asked to report the extent to which they had approached this writing task in a problemsolving-oriented manner and as to how instrumental they evaluated their goal-related means. Next, a manipulation check assessed the participants' situational self-awareness. Lastly, after assessing some sociodemographic background information, participants were debriefed and dismissed.

\section{Measures}

\section{Dispositional Self-Awareness}

Before the manipulations, participants completed the same measure of dispositional self-awareness as in Studies 1a and $1 \mathrm{~b}(\alpha=.95)$. Based on prior studies with MTurk samples, we expected dispositional self-awareness to be negatively skewed, which also proved to be the case in this study $(M=4.55, S D=1.03$, skewness $=-.71, S E=.13)$. To reduce this skew, we used a reverse score and log transformation (Field, 2013) $\left(M_{\log }=1.43, S D_{\log }=0.19\right.$, skewness $\log =.18$, $\left.S E_{\log }=.13\right)$. In identifying and transforming negatively skewed data, we relied on literature (Field, 2013) suggesting to first identify normality in big samples using visual inspection via frequency distribution graphs and q-q-plots, and second, transform negatively skewed data by reversing the scores via reverse score transformation, then log transform them and finally, reverse the scores back.

\section{Problem-Solving Orientation}

Based on the results of a pilot study, which is reported on our OSF account, this task was designed as a creative task that did not require any special knowledge but demanded a general orientation toward problem-solving from participants. Furthermore, the task goal and way of attaining the goal were intended to remain relatively vague, and no optimal solution was given (see Coats et al., 2014; Frensch \& Funke, 1995). The main instruction was to write an interesting text about the word "tie." Participants were told that the word could have different meanings, and it was up to them about which of these meanings and what type of text they would write (e.g., an essay, a newspaper article, a fairytale). Additionally, participants were told that they must not copy the text from the Internet and write at least 400 words. The actual number of written words was displayed to participants. No further information was given. After writing the text, participants were asked to think about how they had solved the writing task. Problem-solving orientation was then measured using the same two items as in Studies 1a and 1b (INCOPE; Bodenmann, 2000), slightly adapted to match better the writing task: "I thought very carefully about the task and what to do." and "I very actively tried to improve my text." Response scales for these items ranged from $1=$ strongly disagree to $7=$ strongly agree $)(M=6.25, S D=0.92, r=.64, p<.001)$. 

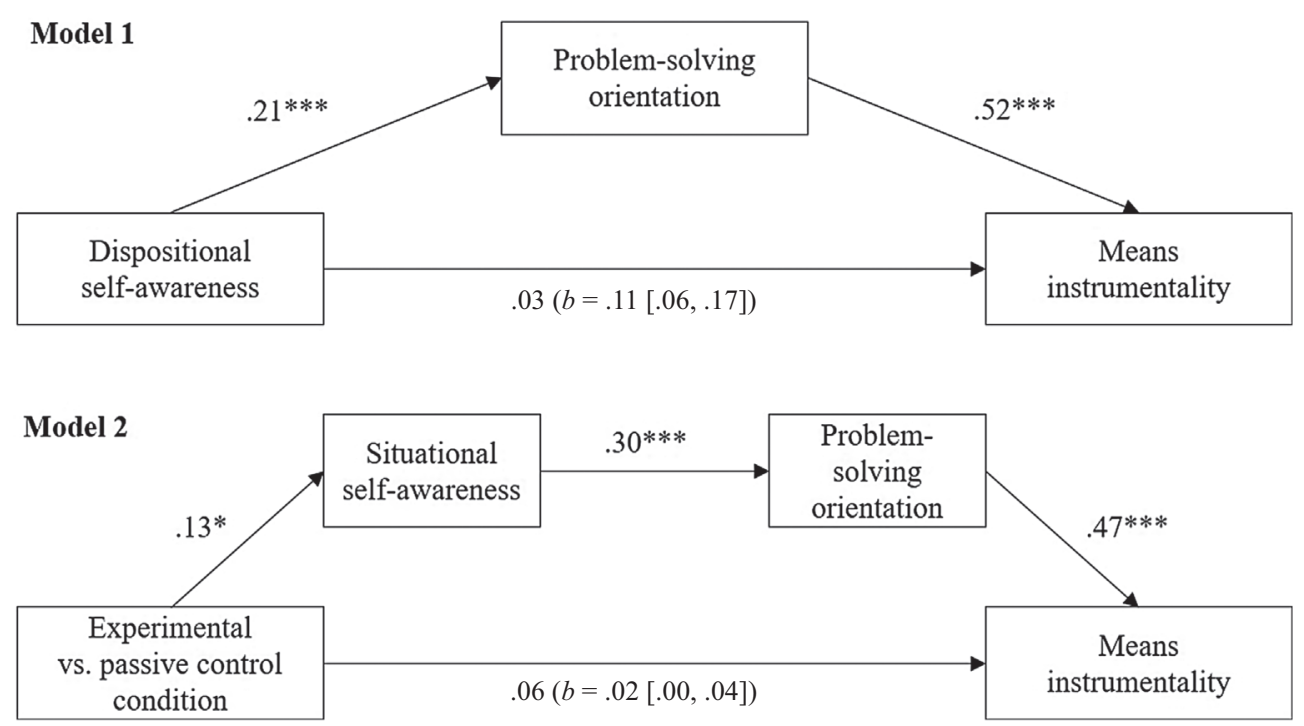

Figure 1. Mediation models from Study 2. The coefficients are standardized regression weights. All analyses are controlled for the subsample. Coefficients in parentheses represent indirect effects [and confident intervals]. The $95 \%$ bias-corrected confidence intervals of the indirect effects were calculated using bootstrapping (5,000 samples). ${ }^{*} p<.05 ; * \star * p<.001$.

\section{Means Instrumentality}

Participants' evaluation of means instrumentality was measured with one item, adapted from Hennecke (2019), which asks participants "As how effective do you consider the way you solved this writing task?", which they answered on a scale ranging from $1=$ not at all effective to $10=$ extremely effective $(M=8.23, S D=1.87)$.

\section{Manipulation Check of Situational Self-Awareness}

As a manipulation check, situational self-awareness was measured using the three items from the "private" factor of the Situational Self-Awareness Scale (SSAS; Govern \& Marsch, 2001), for example, "Right now, I am aware of my innermost thoughts", which we aggregated $(\alpha=.83)$. Response scales ranged from $1=$ strongly disagree to $7=$ strongly agree $(M=4.55, S D=1.03)$.

\section{Concentration}

We furthermore wanted to ensure that possible effects of our experimental manipulations were not due to differences with regard to the cognitive load they impose on participants. As a proxy for cognitive load, we therefore, measured participants' degree of concentration while working on the writing task (Sörqvist et al., 2016) using one item: "I was very focused while completing this study" ( $1=$ strongly disagree to $7=$ strongly agree). As participants' concentration did not differ between the two conditions, we did not further control for this variable $(t(351)=-0.72, p=.475, d=$ 0.07; experimental condition: $M=6.71, S D=0.75$; control condition: $M=6.66, S D=0.71$.

\section{Results}

\section{Effects of Dispositional Self-Awareness}

First, we could replicate the effect of dispositional selfawareness on problem-solving, $r=.22, p<.001$. To show the hypothesized indirect effect of dispositional self-awareness on subjective means instrumentality, we furthermore computed a regression-based mediator analysis using 5,000 bootstraps with the Hayes $(2012,2013)$ procedure using the PROCESS macro for SPSS. As Figure 1 (Model 1) shows, our data confirmed the hypothesized indirect effect of dispositional self-awareness on means instrumentality through problem-solving, $b=.11,95 \%$ CI $[.0600$, $.1675]$.

\section{Effects of the Experimental Manipulation of Self- Awareness}

We then turned to investigate the effects of self-awareness enhancing manipulation on problem-solving and means instrumentality. According to the manipulation check, participants in the experimental condition reported significantly higher situational self-awareness $(M=5.46, S D=$ 1.31) than participants in the control condition $(M=5.14$, $S D=1.23), t(351)=2.39, p=.017$. Moreover, we checked whether dispositional self-awareness interacted with the self-awareness enhancing manipulation predicting situational self-awareness. Results indicated no significant interaction term, $\Delta R^{2}=.00, \Delta F(1,349)=0.25, b=.10, t(349)=$ $0.16, p=.876$.

As the purpose of our manipulation was to increase participants' situational self-awareness, which was hypothesized 
to affect their situational problem-solving, we continued with mediation analyses. We used situational self-awareness as a second mediator. We based this procedure on literature recommending that measures of compliance, which is in our case the manipulation check of situational self-awareness, can be used as a mediator variable (Kenny \& Judd, 2014). As Figure 1 (Model 2) shows, a regression-based mediator analysis with 5,000 bootstraps confirmed the indirect positive effect of the self-awareness enhancing manipulation on means instrumentality through increased situational self-awareness and a stronger orientation toward problem-solving, $b=.02,95 \%$ CI [.0042, .0368]. Based on the common causal-steps approach for investigating mediation (Baron \& Kenny, 1986; Judd \& Kenny, 1981), mediation analyses require a significant direct effect. Please note that we rely on literature claiming several concerns on this approach and pointing out that the only requirement to establish mediation should be a significant indirect effect (e.g., Zhao et al., 2010).

\section{Discussion}

In Study 2, the results of a mediation analysis were consistent with a possible mediational effect of dispositional self-awareness on means instrumentality through problemsolving. Furthermore, after receiving a self-awareness enhancing manipulation, we showed that people reported higher situational self-awareness, which was associated with a stronger orientation toward problem-solving and higher subjective means instrumentality in the writing task. However, apart from the effect of the self-awareness enhancing manipulation on situational self-awareness, the remaining data is correlational and thus does not allow alternative causal models to be excluded (Fiedler et al., 2011). Furthermore, a major limitation of this experimental study is that it assessed means instrumentality through selfreport only. Thus, we do not know how instrumental the selected means actually are. We, therefore, conducted Study 3 , in which we additionally assessed objective goal performance as a proxy to determine the instrumentality of the means participants select to pursue a personal goal.

\section{Study 3}

In this longitudinal Study 3, we again investigated the full causal chain, according to which dispositional self-awareness predicts means instrumentality through problem-solving orientation. To complement our previous measure of subjective means instrumentality with an objective assessment, we studied how participants evaluated their means while pursuing a new goal, more concretely preparing for their first-year university exam, and additionally assessed the extent to which the instrumentality of these means predicted actual exam performance.

\section{Method}

\section{Participants and procedure}

Study 3 was a longitudinal study with two measurement points (T1 and T2). Power analyses (Kenny, 2017) revealed that with 102 participants, we would replicate the indirect effect from Study $2(b=.11)$ with $80 \%$ power at a significance level of $5 \%$.

We recruited first-year students of psychology and mechanical engineering, all of whom pursued the goal of passing their first-year exam. The sample at $\mathrm{T} 1$ contained $N=118$ participants $(74$ psychology students and 44 mechanical engineering students) with a mean age of 22.03 years ( $S D=4.11,53 \%$ female). At T2, 105 of these participants completed the survey, and 95 of them gave their consent to have their final exam grades released to us by the university. Although students of psychology and mechanical engineering did not differ about the main study variables, we nevertheless added the subsample as a control variable to all analyses.

\section{Procedure}

Participants were surveyed twice: 1 month prior to their first-year exam and 2 weeks after the exam. At T1, participants were asked to provide information about several state and trait variables, including their levels of dispositional self-awareness and problem-solving. Furthermore, they listed the means they had used so far for pursuing their goal to pass their first-year exam, as well as the means they anticipated using in the future to pursue this goal. In addition, participants evaluated each means in terms of how instrumental it had been so far or how instrumental they expected it to be. At T2, the means that participants anticipated using were presented again, and participants evaluated how instrumental each of them had been while they were striving for the study goal. Finally, participants were asked to give their consent for their exam grades to be released by the university and were debriefed.

\section{Measures}

\section{Dispositional Self-Awareness}

Participants completed the same measure of dispositional self-awareness as in all other studies (SRIS-SR; Grant et al., 2002) $(M=4.55, S D=0.91, \alpha=.92)$.

\section{Problem-Solving Orientation}

Participants answered the same two items as in Studies 1a and $1 \mathrm{~b}$ to assess their problem-solving orientation (INCOPE; Bodenmann, 2000) $(M=3.71, S D=0.74)$. Again, the two items were moderately correlated $(r=.46, p<.001)$. 


\section{Means Instrumentality}

We assessed the instrumentality of students' previously used means as well as the instrumentality of the means they used during our study. Means were described as all aspects which contribute to the attainment of a goal (Shah \& Kruglanski, 2003). At T1, we asked participants to name all the means they had used so far to reach their study goal and to name all means they anticipated using in their future goal pursuit. On average, participants named $5.20(S D=$ 2.49) past means and $4.15(S D=2.32)$ future ones (e.g., index cards, ambition, coffee, sports, timetable, past exams, study groups). The number of past and future means was highly correlated, $r=.65, p<.001$. Both at $\mathrm{T} 1$ and $\mathrm{T} 2$, participants had to evaluate the instrumentality of their means. For assessing means instrumentality, participants were asked "As how effective do you consider each goal means for the successful achievement of your study goal?" (scale ranging from $1=$ not at all effective to $7=$ very effective) at T1 (past means: $M=5.79, S D=0.77$; future means: $M=$ $5.87, S D=0.91)$ and at T2 $(M=4.96, S D=1.35)$. Means instrumentality at $\mathrm{T} 1$ and $\mathrm{T} 2$ were moderately correlated, $r=.31, p=.001$.

\section{Exam Performance}

We accessed participants' exam scores through the university administration. For psychology students, we were told the number of points they achieved in the exam. For mechanical engineering students, we were told their grade score, which could range from 6 (highest grade) to 1 (lowest grade) with intervals of 0.01 . To obtain comparable scores for goal performance for the two student groups, we transformed the number of points psychology students had obtained and the grades mechanical engineering students had obtained into percentages, with a maximum of 510 points being $100 \%$ performance for psychology students and a maximum grade of 6 being 100\% performance for mechanical engineering students. On average, psychology students $(M=66.51, S D=11.69)$ and mechanical engineering students $(M=70.10, S D=13.11)$ did not differ in their percentage-based goal performance, $t(93)=$ $1.40, p=.165, d=0.29$.

\section{Results and Brief Discussion}

To test the hypothesized mediation model in which dispositional self-awareness positively affects exam performance through two mediators, problem-solving orientation and subjective means instrumentality, we computed a regression-based mediator analysis using 5,000 bootstraps (Hayes, 2012, 2013). We indicated two control variables in our analyses. First, we controlled for the subsample (psychology vs. mechanical engineering students). Second, in order to demonstrate a temporal sequence of our effect, we controlled for means instrumentality at T1. In doing so, we separated changes over time from the initially existing instrumentality of previously used means. We hypothesized that students at the beginning of their studies have less knowledge on the instrumentality of their study-related means (irrespective of their levels of dispositional selfawareness), but a problem-solving orientation in their studies might help self-aware individuals over time to identify and select those means that are instrumental to them. The data from these analyses showed the hypothesized effect: Through their increased problem-solving orientation, participants with greater levels of dispositional self-awareness evaluated their means as being more instrumental over time which was associated with a better performance in their exam (see Figure 2 (Model 2), $b=.04,95 \% \mathrm{CI}$ [.0046, .1405]).

In sum, the data from Study 3 showed the positive effect of self-awareness on means instrumentality through a stronger orientation toward problem-solving again. Furthermore, those means, proved to be highly instrumental as they were associated with students' performance in their first-year exams.

\section{General Discussion}

Successful goal pursuit hinges on selecting instrumental means (Kruglanski et al., 2002; Locke \& Latham, 1990). In the present research, we took an individual-differences perspective on means selection by investigating whether self-awareness (e.g., Duval \& Wicklund, 1972), positively affects problem-solving orientation (e.g., Burwell \& Shirk, 2007), promotes means instrumentality in different forms of difficult goal pursuit.

In a first step, we showed in correlational Studies 1a and $1 \mathrm{~b}$ that participants with higher levels of dispositional self-awareness do indeed report a stronger problem-solving orientation when confronted with stressors in goal pursuit. To obtain evidence for the causal relation between selfawareness and problem-solving orientation, on the one hand, and to show that the stronger orientation toward problem-solving does, in turn, promote means instrumentality, on the other hand, we conducted and preregistered experimental Study 2. In this study, we demonstrated a positive effect of self-awareness enhancing manipulation on subjective means instrumentality through increased situational self-awareness and problem-solving orientation to pursue a vague goal. Lastly, in Study 3, we went a step further and aimed at showing that participants' dispositional selfawareness not only affects subjective (self-reported) means instrumentality but that those means turn out to be highly instrumental as they are associated with better performance 


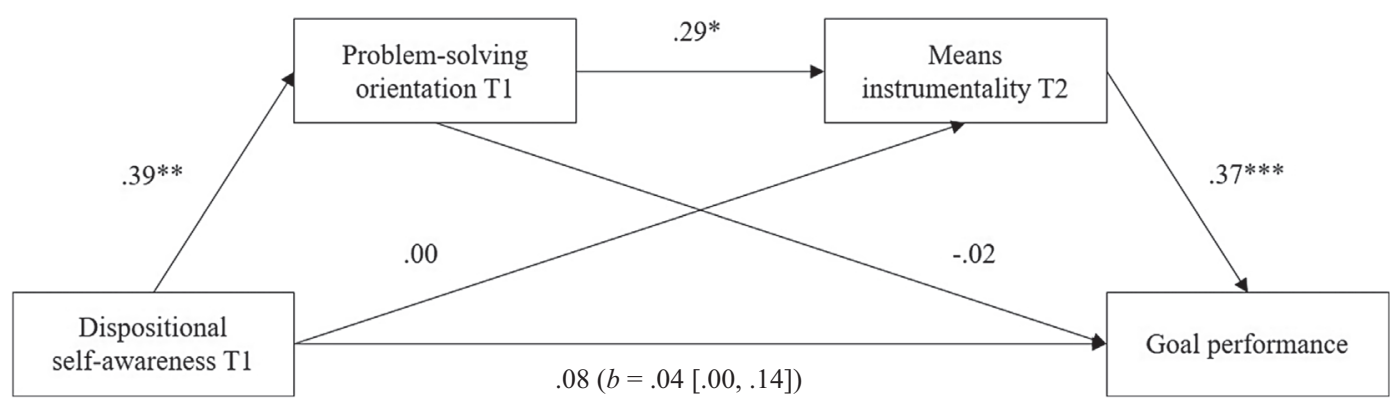

Figure 2. Mediation models with multiple mediators from Study 3. Model 1 is controlled for sub-sample. Model 2 is controlled for sub-sample and means instrumentality at the first measurement occasion. The coefficients are standardized regression weights. The 95\% bias-corrected confidence intervals of the indirect effects were calculated using bootstrapping $\left(5,000\right.$ samples). ${ }^{\star} p<.05 ; \star \star p<.01 ;{ }^{\star} * \star p<.001$.

(academic performance retrieved from official records) in the pursuit of a new goal. Participants with higher dispositional self-awareness did, in fact, obtain better study grades due to the hypothesized mediational effect. This demonstrates that self-awareness through its increased orientation toward problem-solving in goal striving promotes the selection of means that promote goal attainment.

\section{Theoretical Implications}

By focusing on the role of self-awareness and problemsolving for the selection of instrumental means, which is regarded as a highly important self-regulatory process (Kruglanski et al., 2002), we are contributing to the existing research as follows:

Firstly and most importantly, we apply an individualdifferences perspective to the study of means selection, thereby highlighting the importance of individual differences for self-regulatory processes, as previously stressed by different researchers (Duckworth et al., 2007; Hoyle, 2010; Kuhl, 1992; Tangney et al., 2004). We followed up the claim made by Hoyle (2010), who pointed out that self-regulation research rarely discusses the role of individual differences in self-regulatory processes. Moreover, we broaden the perspective of well-established theories which emphasize the importance of means selection, such as goal system theory (Kruglanski et al., 2002), which addresses "the problem of choice among the means" (p. 358). Likewise, research in the realm of goal-setting theory has emphasized the importance of selecting goal-directed strategies as a key mechanism that explains why specific, difficult goals boost performance (Locke \& Latham, 1990). In the same vein, the concept of implementation intentions (Gollwitzer, 1999) underscores the selection of critical situations (i.e., when and where to act on one's goal) and connecting these to concrete goal-directed behaviors (i.e., means). Neither of these theories has, however, specified factors that enable people to select instrumental means. We target this issue by focusing on an individual difference construct, self-awareness, which has been shown to play a key role in self-regulation (Baumeister et al., 1994; Carver \& Scheier, 1998; Duval \& Wicklund, 1972).

Second, we highlight the functional aspects of selfawareness by investigating its reflective side, in contrast to earlier research which primarily focused on the maladaptive consequences of anxiety-driven rumination (e.g., for an overview, see Nolen-Hoeksema et al., 2008). Our research proposes that self-awareness might be highly adaptive in goal pursuit since self-aware individuals command a higher problem-solving orientation. Although the important role of introspection for problem-solving has already been addressed (Jäkel \& Schreiber, 2013), less is known about its underlying cognitive mechanisms. We claim that in the context of goal striving, both the goal and the momentary goal state become salient by directing awareness toward the self, which results in a stronger motivation and greater success in reducing any discrepancy between them (Carver $\&$ Scheier, 1998). If discrepancy reduction cannot easily be done, individuals adopt a problem-solving orientation aiming at the selection of instrumental means. Indeed, we have hypothesized and found that (both dispositionally and situationally) self-aware individuals report an increased problem-solving orientation in their goal striving. One might wonder how situational levels of self-awareness differ from dispositional ones. We propose that situational levels of self-awareness promote a situational state of viewing goal striving as a continuous problem-solving process that aims at reducing goal-related discrepancies with the help of instrumental means. However, individuals with greater levels of dispositional self-awareness should more often get into this state which might induce a more trait-like problem-solving orientation in them. Please note that we have focused on a consciously accessible form of selfawareness during which individuals become the object of their attention. This form of metacognition may have to be distinguished from a more pre-reflective, implicit, and bodily form of self-awareness (Zahavi, 1999). Given that people can pursue goals without conscious awareness 
(e.g., Bargh, 1990), it is conceivable that the cascade of processes we have described here can operate outside of consciousness as well and be triggered by a more implicit form of self-awareness. Future research would have to address this open question.

Third, we highlight the importance of problem-solving in personal goal striving. Especially when individuals cannot pursue their goals automatically or very easily when there are many different options to do so or the goal is rather vague, adopting a problem-solving orientation should be useful for means selection. This conceptualization of problem-solving contributes to and extends previous research investigating problem-solving in everyday life in several ways (e.g., Broadbent \& Aston, 1978; Frensch \& Funke, 1995; Lazarus \& Folkman, 1984): First, we have identified an individual difference that appears to matter for the inclination to approach goal pursuit with a problem-solving orientation, namely self-awareness. This is in line with self-regulatory theories, which propose that an individual's level of self-awareness contributes to their goal attainment through its positive effect on goal monitoring (Carver \& Scheier, 1998). Second, we have focused on a selfregulatory implication of problem-solving, namely for the instrumentality of selected means' during goal pursuit. So far, the instrumentality of selected means had been operationalized in problem-solving research by counting the number of different strategies a person used or through expert ratings (Coats et al., 2014). However, such indices neglect individuals' own ideas of what constitutes an effective solution for a given problem. Our measures included both an objective indicator (i.e., grades) as well as a subjective measure of means instrumentality. Lastly, the problems we investigated had different characteristics which might have provoked problem-solving. According to theoretical definitions, a problem is understood as ill-defined when either the initial state, the desired state, or the means are vague and when, in addition, several means are possible for its solution, but no optimal solution is known (e.g., Simon, 1973). With regard to personal goals, many different reasons can lead to one or more of these components becoming vague. In our research, the ill-defined problems were either personal goals burdened by stressors (Studies 1a and 1b), vaguely defined goals (Study 2), or new goals (Study 3). We assumed that at least one of the components was vague across these goals, but we did not explicitly assess or manipulate this factor. Future research might therefore investigate explicitly which characteristics a problem during goal pursuit must have in order to provoke problem-solving.

Finally, we conceive of means instrumentality as a presumably variable characteristic because a means that is instrumental for a goal at one point in time may not be so throughout the entire course of goal pursuit. For success, it is imperative that people constantly monitor and use feedback about the instrumentality of a given means to potentially adjust their behavior and substitute an existing means with one that provides a better fit to the current demands. Due to the fact that self-awareness is associated with greater goal monitoring (Carver \& Scheier, 1998), future lines of research might investigate whether dispositionally self-aware individuals are also more likely to monitor their means' instrumentality and adapt their means to the current demands. This would imply that the influence of self-awareness on means' instrumentality would be flexible by adapting means to current demands than statically by simply having people choose the best means at goal initiation. Accordingly, self-awareness might promote regulatory flexibility, an individual-difference constructs previously described in the context of emotion regulation and coping with describing individuals' flexibility in adapting regulatory strategies (i.e., means) depending on feedback on their instrumentality (Bonanno \& Burton, 2013). Certainly, this assumption requires empirical evidence. For example, a study capitalizing on experience sampling (e.g., Bolger \& Laurenceau, 2013) could investigate regulatory flexibility as an intra-individual process that should be observed more in people with high levels of selfawareness and people with a higher orientation toward problem-solving.

\section{Strengths and Limitations}

This research has some strengths and limitations that should be addressed. One of its clear strengths is that we followed recommendations regarding cumulative science (e.g., Jasny et al., 2011) by replicating our hypothesized correlational effect of Studies $1 \mathrm{a}$ and $1 \mathrm{~b}$ in all other studies and the hypothesized mediational effect Study 2 in Study 3. We furthermore preregistered our experimental study (Study 2) in order to increase the transparency, rigor, and reproducibility of our research (e.g., Nosek et al., 2018). Speaking in favor of at least some generalizability of our findings, we were able to demonstrate these effects both during the pursuit of personal goals (Studies 1a, 1b, and 3) and the pursuit of instructed goals (Study 2), and in both student samples and MTurk samples, which are shown to be more diverse (Goodman et al., 2013). Finally, circumventing constraints of self-reporting (e.g., Meade \& Craig, 2012), we assessed objective goal performance, namely exam grades, as an objectively measured consequence of the selection of instrumental means.

However, most of our data nevertheless rely on selfreporting, which contains sources of bias like social desirability (Brenner \& DeLamater, 2016) or careless answering (Meade \& Craig, 2012). We cannot rule out the possibility that the participants in our studies gave socially desirable 
answers, as dispositional self-awareness might be viewed as a valued skill. By experimentally inducing self-awareness and preregistering exclusion criteria in Study 2 (e.g., if the writing task is not conducted seriously or is copied in part of fully from the Internet), we tried to allow for participants' careless answering. Furthermore, informing participants about the writing task at the beginning of the study, we followed best practice recommendations to prevent dropouts (Zhou \& Fishbach, 2016). However, it should be mentioned that we had to exclude considerably more data from the experimental study due to our exclusion criteria than we had expected in advance (30\% data exclusion). High data drop-out is always detrimental and raises the question of data quality. In our case, we had preregistered all our exclusion criteria. But for future research, we would recommend using experimental tasks that leave less room for participants to answer carelessly, for example, by using a more interesting topic to write about or adding additional incentives for completing texts that fulfill certain criteria.

In a similar vein, we assessed problem-solving orientation in our studies using two items from an established measure for assessing general problem-solving tendencies (INCOPE; Bodenmann, 2000), which were moderately correlated. This could mean that problem-solving itself entails several facets on a cognitive (first item: "I think very carefully about what's going on and what to do") and a behavioral level (second item: "I actively influence the situation.") which is in line with the conceptualization of problem-solving as a highly complex process consisting of several distinct components (Care, 2017). In future research, it would be fruitful to assess problem-solving orientation differently in its entire breadth and investigate the different facets of problem-solving and its relation to self-regulatory processes more closely.

Furthermore, in our experimental study, we manipulated situational self-awareness, but only with the same small effect size as in previous research using the same manipulation (Kreibich et al., 2020). This suggests that strong shifts in self-awareness are not easily created experimentally. Other researchers have already pointed out that creating strong shifts in attention might be difficult, especially in online settings (e.g., Silvia \& Eichstaedt, 2004).

Lastly, in our experimental study, we assessed means instrumentality by asking participants how instrumental they considered their selected means. As we assessed means instrumentality right after finishing the task, one might argue that participants who experienced the task as being easier will have rated their means as being more instrumental or even their way of handling the task as being more problem-solving-oriented. This would, in turn, imply that the self-awareness enhancing manipulation, which led to more problem-solving and means instrumentality, would have made the task easier. However, the data from Study 3 showed no differences between the groups regarding their concentration, which has been shown to be a useful proxy for the cognitive load (Sörqvist et al., 2016). Accordingly, it is unlikely that cognitive load and task difficulty differed largely across the experimental conditions.

\section{Conclusion}

In this research, we tested the hypothesis that individuals with higher levels of self-awareness, that is, a state of heightened attention to one's thoughts, feelings, and behavior (Duval \& Wicklund, 1972), tend to engage more in problem-solving, which should result in the selection of more instrumental means. In several studies, we obtained evidence for this hypothesis by showing that dispositional self-awareness was indeed correlated with a stronger orientation toward problem-solving (Studies 1a and 1b). Furthermore, both dispositional and experimentally induced self-awareness was positively correlated with problem-solving orientation and resulted in greater subjective means instrumentality in an online writing task (Study 2). Finally, participants' dispositional self-awareness predicted participants' final exam grades (Study 3), and this effect could be explained through their higher engagement in problem-solving and the selection of instrumental means. Overall, this research provides initial evidence that selfawareness and problem-solving are crucial predictors for an important but understudied self-regulatory aspect of goal striving, namely selecting instrumental goal-conducive means.

\section{References}

Bargh, J. A. (1990). Auto-motives: Preconscious determinants of social interaction. In E. T. Higgins \& R. M. Sorrentino (Eds.), Handbook of motivation and cognition (Vol. 2, pp. 93-130). Guilford Press.

Baron, R. M., \& Kenny, D. A. (1986). The moderator-mediator variable distinction in social psychological research: Conceptual, strategic, and statistical considerations. Journal of Personality and Social Psychology, 51(6), 1173-1182. https://doi.org/ 10.1037/0022-3514.51.6.1173

Baumeister, R. F., Heatherton, T. F., \& Tice, D. M. (1994). Losing control: How and why people fail at self-regulation. Academic Press.

Bélanger, J. J., Schumpe, B. M., Lafrenière, M.-A. K., Giacomantonio, M., Brizi, A., \& Kruglanski, A. W. (2016). Beyond goal commitment: How expectancy shapes means evaluation. Motivation Science, 2(2), 67-84. https://doi.org/10.1037/mot0000031

Bodenmann, G. (2000). Stress und coping bei paaren [Stress and coping in couples]. Hogrefe.

Bolger, N., \& Laurenceau, J.-P. (2013). Intensive longitudinal methods: An introduction to diary and experience sampling research. Guilford Press. 
Bonanno, G. A., \& Burton, C. L. (2013). Regulatory flexibility: An individual differences perspective on coping and emotion regulation. Perspectives on Psychological Science, 8(6), 591-612. https://doi.org/10.1177/1745691613504116

Brenner, P. S., \& DeLamater, J. (2016). Lies, damned lies, and survey self-reports? Identity as a cause of measurement bias. Social Psychology Quarterly, 79(4), 333-354. https://doi.org/ 10.1177/0190272516628298

Broadbent, D. E., \& Aston, B. (1978). Human control of a simulated economic system. Ergonomics, 21(12), 1035-1043. https://doi. org/10.1080/00140137808931810

Burwell, R. A., \& Shirk, S. R. (2007). Subtypes of rumination in adolescence: Associations between brooding, reflection, depressive symptoms, and coping. Journal of Clinical Child \& Adolescent Psychology, 36(1), 56-65. https://doi.org/10.1080/ 15374410709336568

Care, E. (2017). Assessment and teaching of 21 st century skills: Research and applications. Springer.

Carver, C. S., \& Scheier, M. F. (1982). Control theory: A useful conceptual framework for personality - social, clinical, and health psychology. Psychological Bulletin, 92(1), 111-135. https://doi.org/10.1037/0033-2909.92.1.111

Carver, C. S., \& Scheier, M. F. (1998). On the self-regulation of behavior. Cambridge University Press.

Coats, A. H., Hoppmann, C., \& Scott, S. B. (2014). Goals, strategies, and well-being across adulthood: Integrating perspectives from the coping and everyday problem-solving literatures. In P. Verhaeghen \& C. Hertzog (Eds.), The Oxford handbook of emotion, social cognition, and problem solving in adulthood (pp. 206-221). Oxford University Press.

Costa, P. T. Jr., \& McCrae, R. R. (1992). Revised NEO Personality Inventory (NEO-P1-R) and NEO Five-Factor Inventory (NEO-FF1) professional manual. Psychological Assessment Resources.

Dörner, D., \& Reither, F. (1978). Über das Problemlösen in sehr komplexen Realitätsbereichen [On problem solving in very complex domains of reality]. Zeitschrift für Experimentelle und Angewandte Psychologie, 25(4), 527-551.

Duckworth, A. L., Peterson, C., Matthews, M. D., \& Kelly, D. R. (2007). Grit: Perseverance and passion for long-term goals. Journal of Personality and Social Psychology, 92(6), 1087-1101. https://doi.org/10.1037/0022-3514.92.6.1087

Duncker, K. (1945). On problem-solving. American Psychological Association.

Duval, S., \& Wicklund, R. A. (1972). A theory of objective self awareness. Academic Press.

Evans, D. R., Baer, R. A., \& Segerstrom, S. C. (2009). The effects of mindfulness and self-consciousness on persistence. Personality and Individual Differences, 47(4), 379-382. https://doi.org/ 10.1016/j.paid.2009.03.026

Faul, F., Erdfelder, E., Lang, A.-G., \& Buchner, A. (1992-2019). G*Power 3.1.9.4: A flexible statistical power analysis program for the social, behavioral, and biomedical sciences. Behavior Research Methods, 39(2), 175-191. https://doi.org/10.3758/bf03193146

Fenigstein, A., Scheier, M. F., \& Buss, A. H. (1975). Public and private self-consciousness: Assessment and theory. Journal of Consulting and Clinical Psychology, 43(4), 522-527. https://doi. org/10.1037/h0076760

Fiedler, K., Schott, M., \& Meiser, T. (2011). What mediation analysis can (not) do. Journal of Experimental Social Psychology, 47(6), 1231-1236. https://doi.org/10.1016/j.jesp.2011. 05.007

Field, A. (2013). Discovering statistics using IBM SPSS statistics. Sage.

Fox, M. C., Ericsson, K. A., \& Best, R. (2011). Do procedures for verbal reporting of thinking have to be reactive? A metaanalysis and recommendations for best reporting methods. Psychological Bulletin, 137(2), 316-344. https://doi.org/10.1037/ a0021663
Frensch, P. A., \& Funke, J. (1995). Definitions, traditions, and a general framework for understanding complex problem solving. In P. A. Frensch \& J. Funke (Eds.), Complex problem solving: The European perspective (pp. 3-25). Erlbaum.

Giluk, T. L. (2009). Mindfulness, big five personality, and affect: A meta-analysis. Personality and Individual Differences, 47(8), 805-811. https://doi.org/10.1016/j.paid.2009.06.026

Gollwitzer, P. M. (1999). Implementation intentions: Strong effects of simple plans. American Psychologist, 54(7), 493-503. https://doi.org/10.1037/0003-066X.54.7.493

Goodman, J. K., Cryder, C. E., \& Cheema, A. (2013). Data collection in a flat world: The strengths and weaknesses of mechanical turk samples. Journal of Behavioral Decision Making, 26(3), 213-224. https://doi.org/10.1002/bdm.1753

Govern, J. M., \& Marsch, L. A. (2001). Development and validation of the situational Self-Awareness Scale. Consciousness and Cognition, 10(3), 366-378. https://doi.org/10.1006/ccog.2001. 0506

Grant, A. M., Franklin, J., \& Langford, P. (2002). The self-reflection and insight scale: A new measure of private self-consciousness. Social Behavior and Personality: An International Journal, 30(8), 821-835. https://doi.org/10.2224/sbp. 2002.30.8.821

Hayes, A. F. (2012). PROCESS: A versatile computational tool for observed variable mediation, moderation, and conditional process modeling [White paper]. http://www.afhayes.com/public/ process2012.pdf

Hayes, A. F. (2013). Introduction to mediation, moderation, and conditional process analysis: A regression-based approach. Guilford Press.

Hennecke, M. (2019). What doesn't kill you: Means for avoidance goal pursuit are less enjoyable than means for approach goal pursuit. Motivation Science, 5(1), 1-13. https://doi.org/ 10.1037/mot0000104

Hoyle, R. H. (2010). Handbook of personality and self-regulation. Wiley-Blackwell.

Jäkel, F., \& Schreiber, C. (2013). Introspection in problem solving. The Journal of Problem Solving, 6(1), 20-33. https://doi.org/ 10.7771/1932-6246.1131

Jasny, B. R., Chin, G., Chong, L., \& Vignieri, S. (2011). Again, and again, and again. Science, 334(6060), 1225-1225. https://doi. org/10.1126/science.334.6060.1225

Judd, C. M., \& Kenny, D. A. (1981). Process analysis: Estimating mediation in treatment evaluations. Evaluation Review, 5(5), 602-619. https://doi.org/10.1177/0193841X8100500502

Kenny, D. A. (2017). An interactive tool for the estimation of power in tests of mediation [Computer software]. https://davidakenny. shinyapps.io/PowerMed/

Kenny, D. A., \& Judd, C. M. (2014). Power anomalies in testing mediation. Psychological Science, 25(2), 334-339. https://doi. org/10.1177/0956797613502676

Kreibich, A., Hennecke, M., \& Brandstätter, V. (2019). The role of self-awareness and problem-solving orientation for the instrumentality of goal-related means [Dataset]. https://osf.io/rngfk/

Kreibich, A., Hennecke, M., \& Brandstätter, V. (2020). The effect of self-awareness on the identification of goal-related obstacles. European Journal of Personality, 34, 215-233. https://doi.org/ 10.1002/per.2234

Kruglanski, A. W., Shah, J. Y., Fishbach, A., Friedman, R., Chun, W. Y., \& Sleeth-Keppler, D. (2002). A theory of goal systems. In M. P. Zanna (Ed.), Advances in experimental social psychology (Vol. 34, pp. 331-378). Academic Press.

Kuhl, J. (1992). A theory of self-regulation: Action versus state orientation, self-discrimination, and some applications. Applied Psychology, 41(2), 97-129. https://doi.org/10.1111/j.14640597.1992.tb00688.x

Lazarus, R. S., \& Folkman, S. (1984). Stress, appraisal and coping. Springer. 
Locke, E. A., \& Latham, G. P. (1990). A theory of goal setting and task performance. Prentice-Hall.

Meade, A. W., \& Craig, S. B. (2012). Identifying careless responses in survey data. Psychological Methods, 17(3), 437-455. https:// doi.org/10.1037/a0028085

Nolen-Hoeksema, S., Wisco, B. E., \& Lyubomirsky, S. (2008). Rethinking rumination. Perspectives on Psychological Science, 3(5), 400-424. https://doi.org/10.1111/j.1745-6924.2008.00088.x

Nosek, B. A., Ebersole, C. R., DeHaven, A. C., \& Mellor, D. T. (2018). The preregistration revolution. Proceedings of the National Academy of Sciences, 115(11), 2600-2606. https://doi.org/ 10.1073/pnas. 1708274114

Panah, M. R., \& Seif, D. (2014). Predicting self-awareness dimensions from personality traits among gifted students. Journal of Iranian Psychologists, 10(40), 361-370.

PlagScan. (2020). Online plagiarism checking. https://www.plagscan. com

Schumpe, B. M., Bélanger, J. J., Dugas, M., Erb, H.-P., \& Kruglanski, A. W. (2018). Counterfinality: On the increased perceived instrumentality of means to a goal. Frontiers in Psychology, 9(1052), 1-15. https://doi.org/10.3389/fpsyg.2018.01052

Shah, J. Y., \& Kruglanski, A. W. (2003). When opportunity knocks: Bottom-up priming of goals by means and its effects on selfregulation. Journal of Personality and Social Psychology, 84(6), 1109-1122. https://doi.org/10.1037/0022-3514.84.6.1109

Silvia, P. J., \& Eichstaedt, J. (2004). A self-novelty manipulation of self-focused attention for internet and laboratory experiments. Behavior Research Methods, Instruments, \& Computers: A Journal of the Psychonomic Society, 36(2), 325-330. https:// doi.org/10.3758/BF03195578

Simon, H. A. (1973). The structure of ill structured problems. Artificial Intelligence, 4(3-4), 181-201. https://doi.org/10.1016/ 0004-3702(73)90011-8

Simmons, J. P., Nelson, L. D., \& Simonsohn, U. (2012, October 14). A 21 word solution. https://ssrn.com/abstract $=2160588$

Sörqvist, P., Dahlström, Ö., Karlsson, T., \& Rönnberg, J. (2016). Concentration: The neural underpinnings of how cognitive load shields against distraction. Frontiers in Human Neuroscience, 10(221), 1-10. https://doi.org/10.3389/fnhum.2016.00221

Tangney, J. P., Baumeister, R. F., \& Boone, A. L. (2004). High selfcontrol predicts good adjustment, less pathology, better grades, and interpersonal success. Journal of Personality, 72(2), 271324. https://doi.org/10.1111/j.0022-3506.2004.00263.x

Trapnell, P. D., \& Campbell, J. D. (1999). Private self-consciousness and the five-factor model of personality: Distinguishing rumination from reflection. Journal of Personality and Social Psychology, 76(2), 284-304. https://doi.org/10.1037/00223514.76.2.284

Zahavi, D. (1999). Self-awareness and alterity: A phenomenological investigation (Northwestern University studies in phenomenology and existential philosophy). Northwestern University Press.

Zhang, Y., Fishbach, A., \& Kruglanski, A. W. (2007). The dilution model: How additional goals undermine the perceived instru- mentality of a shared path. Journal of Personality and Social Psychology, 92(3), 389-401. https://doi.org/10.1037/00223514.92.3.389

Zhao, X., Lynch, J. G., \& Chen, Q. (2010). Reconsidering Baron and Kenny: Myths and truths about mediation analysis. Journal of Consumer Research, 37(2), 197-206. https://doi.org/10.1086/ 651257

Zhou, H., \& Fishbach, A. (2016). The pitfall of experimenting on the web: How unattended selective attrition leads to surprising (yet false) research conclusions. Journal of Personality and Social Psychology, 111(4), 493-504. https://doi.org/10.1037/ pspa0000056

\section{History}

Received June 5, 2020

Revision received July 13, 2021

Accepted July 18, 2021

Published online November 12, 2021

\section{Conflict of Interest}

The authors declare no potential conflicts of interest with respect to the research, authorship, and/or publication of this article.

\section{Open Data}

The preregistration of Study 2 can be assessed online at https:// aspredicted.org/zx5jx.pdf

All supplemental materials including the study materials, the verbatim wording of all study variables, analyses scripts, results of additional analyses, and datasets are publicly available on the Open Science Framework https://osf.io/rngfk/ (Kreibich et al., 2019).

\section{Funding}

The authors disclose receipt of the following financial support for the research, authorship, and/or publication of this article: Preparation of this manuscript was supported by Grant 2017-30 from the Foundation of Suzanne and Hans Biaesch for the Advancement of Applied Psychology. Open access publication enabled by Siegen University Library.

\section{ORCID}

Marie Hennecke

(iD) https://orcid.org/0000-0002-0263-4598

\section{Marie Hennecke}

Department of Psychology

University of Siegen

Adolf-Reichwein-Strasse 2a

57068 Siegen

Germany

marie.hennecke@uni-siegen.de 